\title{
脆性材料の強度保証試験法の基礎検討
}

\author{
高 橋一 郎 \\ (神奈川工科大学工学部機械工学科, 243-02 厚木市下荻野 1030)
}

\section{Proof Test for Assuring the Strength of Brittle Materials}

\author{
Ichiro TAKAHASHI
}

Department of Mechanical Engineering, Kanagawa Institute of Technology,
1030, Shimoogino, Atugi-shi, Kanagawa 243-02

A test technique for loading the arbitrary stress and a method for strength evaluation were studied to develop a reliability testing method. (1) The test technique for loading arbitrary stress was developed by using thermal stress. (2) The thermal stress reached a maximum immediatly after cooling, and then decreased monotonically. (3) The maximum thermal stress increased with an increase of both temperature and thickness of specimen. (4) The strength of brittle materials was evaluated by using a relationship between temperature and the maximum stress. [Received March 28, 1988; Accepted April 26, 1988]

Key-words : Proof test, Brittle material, Thermal stress, Glass, Temperature, Strength, Finite element method

\section{1. 緒言}

セラミックスのような脆性材料を機械部品等の強度部 材として使用する場合に障害になる点は, 他の構造用材 料に比べて強度のばらつきが大きいことである. そのた め, 現在は, 強度のばらつきをワイブル統計で解析し, 寸法効果や部材の破壊確率を予測する方法等がとられて いる. しかし, 強度設計上最も重要な破壊確率の極めて 小さい領域で強度がワイブル分布に従わないことや, 平 滑材の強度が $50 \%$ 程度ばらつく材料においてもき裂材 の強度のばらつきは数\%程度と小さいことはよくしられ ている。

一方, セラミックスの破面を観察すると, 破壊の起点 には表面加工傷, 介在物, 粗大粒子, 空孔等の微小な欠 陥が認められることが多い。すなわち，構造用セラミッ クスの破壊鞖性值は構造用鉄鋼材料の数十分の一であ り, 同一の応力が作用する場合の許容欠陥の寸法は百分 の一から千分の一であるから，鉄鋼材料では問題になら ないような微小な欠陥が強度を支配し，このことが強度 のばらつきを大きくしていると考えられる.したがって, セラミックスにおいて得られている強度の大きなばらつ きは材料が本質的に有している強度の統計的性質ではな く，陷分布に依存していると考えられる.

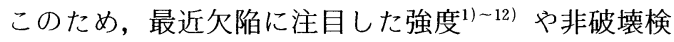
査技術 ${ }^{13) ~ 16)}$ の研究が盛んとなってきている. しかしな がら, X 線や超音波探傷装置等で数十 $\mu \mathrm{m}$ 程度の機械部 品の欠陥を検出する事は困難である. そこで, 回転体で あれば過速試験によって応力を作用させ実機の信頼性を 確保している(7) 18). しかし他の構造体では必要な応力 を負荷する適当な試験法がないのが現状である.
本報では, 部品の強度保証試験法を確立するために任 意の応力を作用させる方法, 及びその強度を評価する手 法を平滑な脆性材料を取り上げ検討する.

\section{2. 実験方法}

供試材には, 非晶質なセラミックスとして, 建築用空 に使用されているフロート板ガラス(ソーダ石英ガラス) を用いた．供試材料の機械的性質を表 1 に示す.

試験片は, 縦 $60 \mathrm{~mm}$, 横 $60 \mathrm{~mm}$, 厚さ $5,3,2 \mathrm{~mm}$ の 3 種類とした。試験片の表面仕上げは, 試験片採取時の 両切断面を 80〜1000 番の炭化ケイ素研磨紙を用いて行 い，他の両表面は受け入れのままとした.

Table 1. Mechanical property of a glass.

\begin{tabular}{|c|c|}
\hline Density $\left(\mathrm{Kg}^{\prime} \mathrm{m}^{3}\right)$ & $2.46 * 10^{3}$ \\
\hline $\begin{array}{c}\text { Young's modulus } \\
(\mathrm{Pa})\end{array}$ & $6.86 * 10^{i *}$ \\
\hline $\begin{array}{c}\text { Poisson' s ratio } \\
\text { Thermal expansion } \\
\left.\text { Coefficient (1/ }{ }^{\circ} \mathrm{C}\right)\end{array}$ & 0.2 \\
\hline $\begin{array}{c}\text { Specific heat } \\
\left.\text { (J/kg }{ }^{\circ} \mathrm{C}\right)\end{array}$ & $9.9 * 10^{-6}$ \\
\hline $\begin{array}{c}\text { Thermal conductivity } \\
\left.\text { (W/m }{ }^{\circ} \mathrm{C}\right)\end{array}$ & $1.15 * 10^{*}$ \\
\hline
\end{tabular}




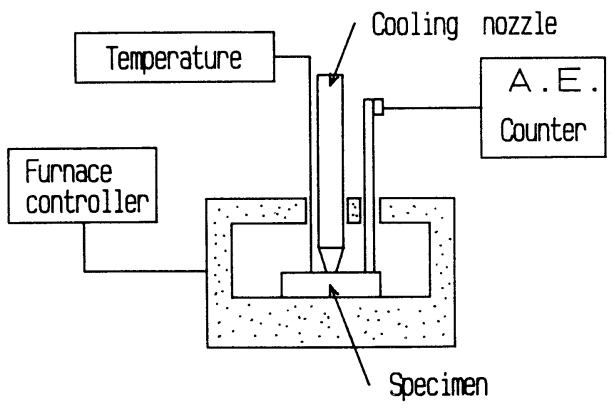

Fig. 1. Schematic of proof test apparatus.

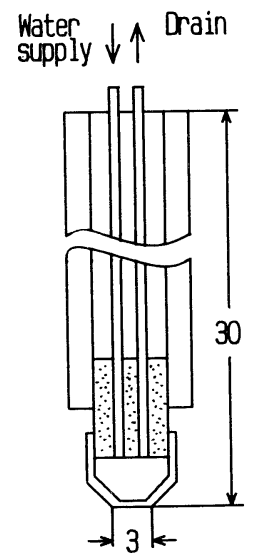

Fig. 2. Schematic of cooling nozzle.

実験装置の概略を図 1 に示す.カンタル線を用いて試 作した加熱炬に試験片を設置し試験温度に加熱する. 昇 温時間は $30 \sim 40 \mathrm{~min}$ で, その後 10〜15 min 保持した後, 試験片に図 2 に示す直径 $3 \mathrm{~mm}$ の水冷式冷却端子を接触 させ熱応力を発生させた. 冷却端子の先端は熱伝導率が 比較的大きいタフピッチ銅を用いた. 冷却方法としては ガスによる直接冷却が考えられるが19)，この方法では熱 伝達率が変化しやすいため本実験では水冷を採用した。 冷却水は約 $15^{\circ} \mathrm{C}$ の水道水を使用し, 流量を $5 \times 10^{-6} \sim$ $1.4 \times 10^{-4} \mathrm{~m}^{3} / \mathrm{s}$ に変えて実験を行った.このとき, 試験 片表面の温度の測定を行うとともに，熱応力によるき裂 の発生の有無を確認するためにA.E. (Acoustic Emission) を用いた. A.E.信号は試験片表面に取り付 けた石英ガラス棒によって炉外に取り出し，A.E. カウ ンターで計数した.

\section{3. 実験結果及び考察}

\section{1 熱負荷実験結果}

図 3 は試験片を $300^{\circ} \mathrm{C}$ に加熱した後, 流量 $1.4 \times$ $10^{-4} \mathrm{~m}^{3} / \mathrm{s}$ の冷却端子を接触させ, 端子中心より $10 \mathrm{~mm}$ の点の温度変化を測定した結果を示す. 温度は時間とと もに単調に減少し, $60 \mathrm{~s}$ で十数 ${ }^{\circ} \mathrm{C}$ 低下する. また, 流 量による温度の変化は本実験の範囲ではあまりなかっ

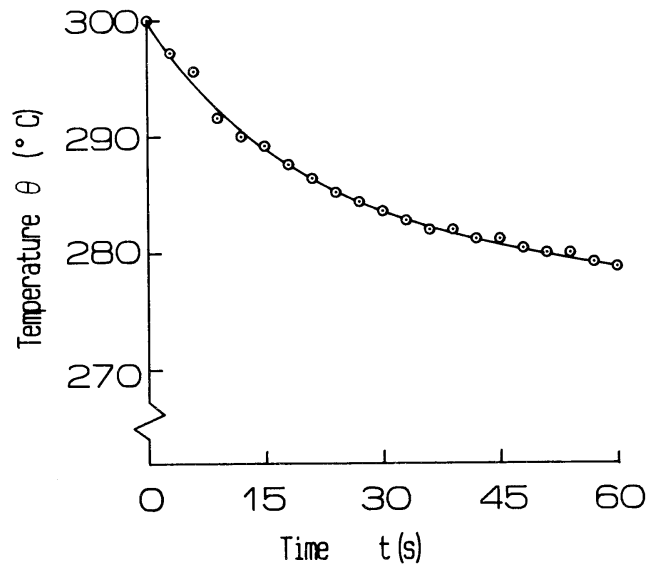

Fig. 3. Relationship between passed time and measured temperature at $10 \mathrm{~mm}$ from the center of a specimen.

Heated temperature $\theta=300^{\circ} \mathrm{C}$,

Thickness of a specimen $h_{1}=5 \mathrm{~mm}$

Table 2. Experimental results for various thermal conditions.

$\bigcirc$ : Initial cracks were observed,

$x$ : Initial crack were not observed

\begin{tabular}{|c|c|c|c|c|c|c|c|}
\hline \multirow{2}{*}{$\begin{array}{c}\text { Flow rate } \\
\left(\mathrm{m}^{3} / \mathrm{s}\right)\end{array}$} & \multirow{2}{*}{$\begin{array}{l}\text { Thickness } \\
\text { of speci- } \\
\text { men (mi) }\end{array}$} & \multicolumn{6}{|c|}{ Heated temperature $\left({ }^{\circ} \mathrm{C}\right)$} \\
\hline & & \multicolumn{2}{|c|}{300} & \multicolumn{2}{|c|}{400} & \multicolumn{2}{|c|}{500} \\
\hline \multirow{3}{*}{$5 * 10^{-6}$} & 2 & & & $x$ & & O & \\
\hline & 3 & $x$ & 0 & $x$ & 0 & 0 & 0 \\
\hline & 5 & $x$ & O & O & O & O & $\mathrm{O}$ \\
\hline \multirow{3}{*}{$1 * 10^{5}$} & 2 & $x$ & $x$ & 0 & 0 & 0 & 0 \\
\hline & 3 & $x$ & $x$ & 0 & 0 & 0 & 0 \\
\hline & 5 & $x$ & 0 & O & 0 & $\mathrm{O}$ & $\mathrm{O}$ \\
\hline \multirow{3}{*}{$1.4 * 10 *$} & 2 & $x$ & $x$ & O & 0 & $\mathrm{O}$ & $\mathrm{O}$ \\
\hline & 3 & $x$ & $\mathrm{O}$ & $x$ & $\mathrm{O}$ & 0 & 0 \\
\hline & 5 & & 0 & & 0 & 0 & $\mathrm{O}$ \\
\hline
\end{tabular}

た。

加熱温度を $300^{\circ} \mathrm{C}$ から $500^{\circ} \mathrm{C}$ までかえ, 流量を $5 \times$ $10^{-6} \sim 1.4 \times 10^{-4} \mathrm{~m}^{3} / \mathrm{s}$ として行った実験結果を表 2 に示 す。○×印はそれぞれ初期き裂の発生の有無を示す。初 期き裂は冷却端子を接触させた瞬間 (1 s 以内)に発生し, その後 2 次的き裂が $5 \sim 15 \mathrm{~s}$ 後に発生及び進展した. 本 実験の範囲では, 流量の増加はき裂の発生の有無に顕著 な影響を与えない。 また, 試験片厚さと加熱温度の増加 にしたがって，き裂が発生しやすくなる.

\section{2 熱負荷応力解析}

試験片に水冷端子を接触させたときに発生する温度分 
布及び熱忍力分布を解析するために有限要素法

(“ANSYS-PC/THERMAL, LINEAR”：サイバネッ トシステム)を用いた。

解析にはアイソパラメトリック要素を用い, 図 4 に示 す分割モデル（節点：288, 要素：255）で非定常温度及 び応力計算を行った. 試験片中央部に冷却端子が接触し たモデルを考慮し, 端子中心から右部を図 4 のように分 割した。試験片上で冷却端子と接触する $\mathrm{a}$ 部とそれ以外 のb部の熱伝達係数 $h, h^{\prime}$ は, 流れている水 $(290$ $\left.5816 \mathrm{~W} / \mathrm{m}^{2}{ }^{\circ} \mathrm{C}\right)$ 及び静止している空気 $\left(1.16 \sim 23 \mathrm{~W} / \mathrm{m}^{2}\right.$ $\left.{ }^{\circ} \mathrm{C}\right)$ の概略值 ${ }^{20)}$ の範囲で, 図 3 に示す温度の実測值と 後述する計算結果を基に推定した。解析には $\mathrm{a}, \mathrm{b}$ 部の 熱伝達係数を仮定し，一様に加熱された試験片の冷却開 始から経過時間毎の温度分布を非定常温度解析プログラ ム (ANSYS-PC/THERMAL) を用いて求めた。また，

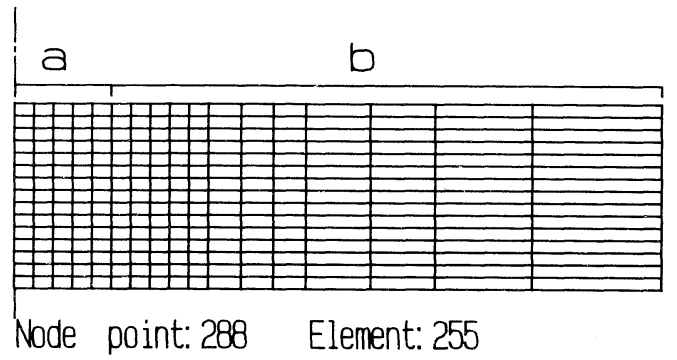

Fig. 4. Mesh model used in finite element calculation.

Part (a) shows the surface contacting with a cooling nozzle and part (b) shows the surface contacting with the air.

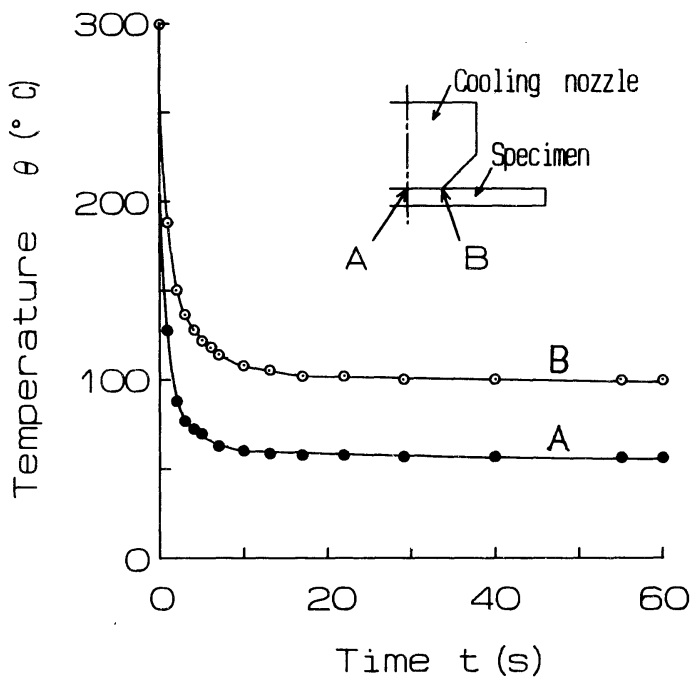

Fig. 5. Relationship between passed time and temperature at point $\mathrm{A}$ and $\mathrm{B}$ after cooling a specimen.

Heated temperature $\theta=300^{\circ} \mathrm{C}$,

Thickness of a specimen $h_{1}=3 \mathrm{~mm}$
応力分布は前述の経過時間毎の温度分布を基に応力解析 プログラム、(ANSYS-PC/LINEAR) を用いて求めた.

図 5 は $300^{\circ} \mathrm{C}$ に加熱した試験片に冷却端子を接触さ せたときの端子中心直下（A 点）と端子端（B点）の 温度変化を示す。両点とも温度は $10 \mathrm{~s}$ 程度まで急激に 低下するが，その後ほぼ一定となる. また, 端子中心直 下である $\mathrm{A}$ 点の方が $\mathrm{B}$ 点よりも温度低下は大きい。

図 6 は図 5 に示した条件下の試験片内部の等温度線図 を冷却開始 $0.2 \mathrm{~s}$ 後と $10 \mathrm{~s}$ 後について示す. 後述のよう に応力が最大となる $0.2 \mathrm{~s}$ 後では端子周辺に大きな温度 こう配があるのに対し，10 s 後では温度こう配も非常に ゆるやかで，ほぼ一様に冷却されていることがわかる．

図 7 は加熱温度を $300^{\circ} \mathrm{C}$ とした時の表面の熱伝達係 数 $h$ (図 4 の a 部) と最大発生応力 $\sigma$ の関係を示す. 熱伝達係数及び試験片厚さが増すにしたがって, 応力は 単調に増加する。本材料の曲げ強度が約 $50 \mathrm{MPa}$ であ ること及び表 2 に示した武験片厚さ $3 \sim 5 \mathrm{~mm}$ の実験結 果を基に，端子接触部の熱伝達係数 $h$ を約 $2500 \mathrm{~W} / \mathrm{m}^{2}$ ${ }^{\circ} \mathrm{C}$ と推定した.

経過時間 $t$ と発生応力 $\sigma$ の関係を図 8 に示す. 各厚 さの試験片とも冷却開始後 $0.2 \mathrm{~s}$ までは応力は増加する が，それ以後時間とともに単調に減少する.このことか
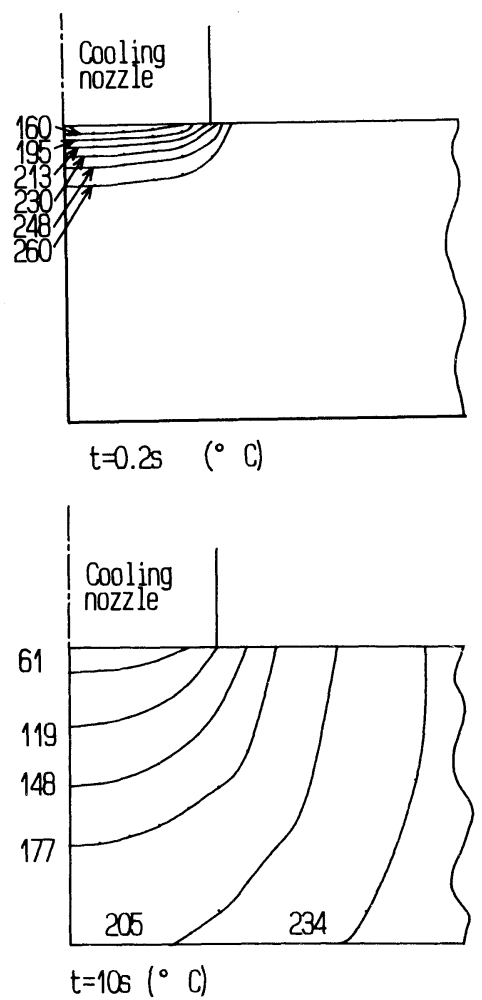

Fig.6. Contour map on temperature of inside of a specimen.

Heated temperature $\theta=300^{\circ} \mathrm{C}$,

Thickness of a specimen $h_{1}=3 \mathrm{~mm}$ 


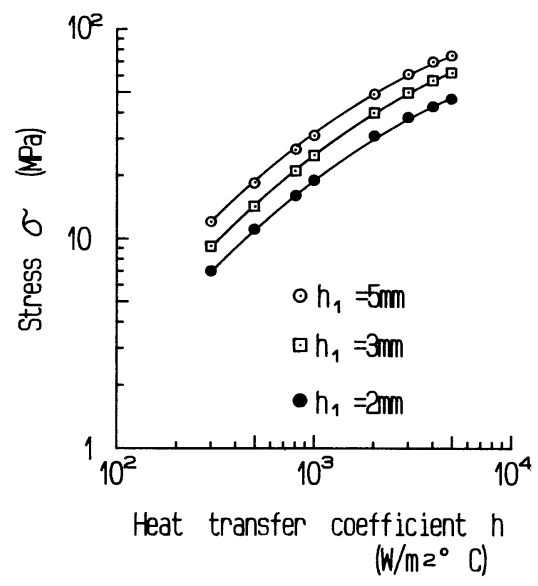

Fig. 7. Relationship between heat transfer coefficient and maximum stress of various specimens.

Heated temperature $\theta=300^{\circ} \mathrm{C}$

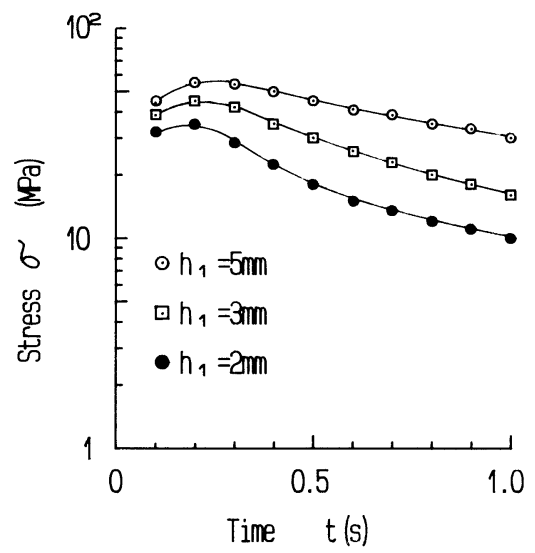

Fig. 8. Relationship between passed time and maximum stress of various specimens.

Heated temperature $\theta=300^{\circ} \mathrm{C}$

ら，最大応力が発生する時間は実験から得られたき裂発 生時間とほぼ一致しているものと考えられる.

加熱温度 $\theta$ と最大発生応力 $\sigma$ の関係を図 9 に示す. また，破線で示した值は曲げ強度の平均值を示す．加熱 温度と試験片厚さを増加するに従って, 応力は増加する. 表 2 に示したき裂の発生状況は，曲げ強度を基準にした 本図によって比較的よく説明できる．すなわち，加熱温 度が $300^{\circ} \mathrm{C}$ では $5 \mathrm{~mm}$ の厚さの試験片に発生する応力は 曲げ強度を超えているため, 多少のばらつきはあるもの

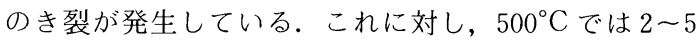
$\mathrm{mm}$ の厚さのすべての試験片に発生する応力が曲げ強度 を超えているためき裂が発生する.

以上より，本報告で検討した手法により任意の応力を 任意の場所に発生させることができるとともに，部材の 強度を評価することができる。

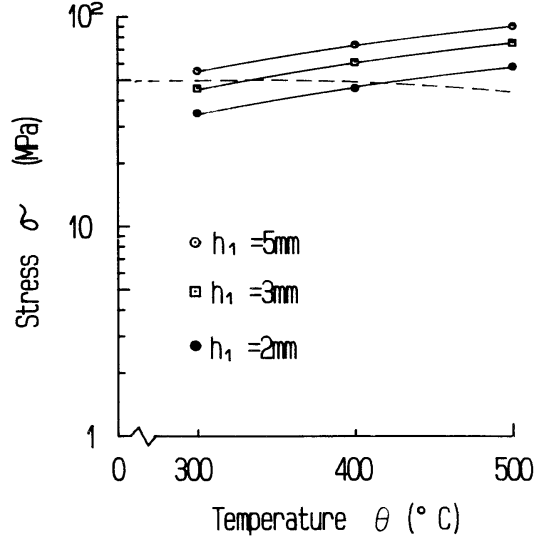

Fig. 9. Relationship between heated temperature and maximum stress of various specimens.

\section{4. 結 言}

部品の信頼性保証試験法を確立するために任意の応力 を作用させる方法及びその強度を評価する手法を検討し た結果，次のような結論が得られた。

（1）熱応力を利用して任意の応力を発生させる手法 を考案した.

（2）発生する応力は冷却を開始してから短時間のう ちに最大となり，その後ゆるやかに減少していく。

（3） 発生する最大応力は加熱温度及び試験片厚さの 増加にしたがって増加する。

（4）加熱温度と最大応力の関係を用いて脆性材料の 曲げ強度を評価することができる.

謝辞 本研究を実施するに当たって本学卒研生・長谷川敏 幸, 渡辺聖一両君のご協力を頂いた。ここに記して謝意を表する。

\section{文献}

1) H.P. Kirchner, R. M. Gruver and W. A. Sotter, Mater, Sci. Eng., 22, 147-56 (1976).

2）井関孝善，丸山忠司，花房啓一，鈴木弘茂，㝘協，86， 47-52 (1978).

3) M. Kawai, H. Abe and J. Nakayama, International Symposium of Factors in Densification and Sintering of Oxide and Non-oxide Ceramics, Japan, 545-52 (1978).

4) W. C. Bourne and R.E. Tressler, Frac. Mech. Ceram., 3, 113-24 (1978).

5) R.W. Rice, S.W. Freiman, R. C. Pohanka, J. J. Mecholsky, Jr. and C. Cm. Wu, Frac. Mech. Ceram., 4, 849-74 (1978).

6) K. R. Mackinney and R. W. Rice, "Fracture Mechanics Methods for Ceramics, Rocks and Concrete", ASTM STP-745 (1981) pp. 118-26

7) H. P Kirchner and E. D. Isaacson, Frac. Mech. Ceram., 5, 57-70 (1983).

8）宇佐美三郎，高橋一郎，木本 寛，日本材料学会第 33 期 学術講演会前刷, 159-61 (1984).

9）山田敏郎, 星出敏彦, 古屋博章, 材料, 33, 28-33(1984).

10）高橋一郎, 宇佐美三郎, 中門公明, 宮田 寛, 志田 茂, 窯協, 93, 186-94 (1985).

11）木本 寛, 宇佐美三郎, 宮田 寛, 日本機械学会論文集 (A 編)，51，2482-88 (1985). 
12) S. Usami, H. Kimoto, I. Takahashi and S. Shida, Eng. Frac. Mech., 23, 745-61 (1986).

13) B. T. Khuri-yakub, G. S. Kino and A. G. Evans, J. Am. Ceram. Soc., 63, 65-71 (1980).

14）小榢 健，山本哲夫，非破壊検査昭和 57 年春期大会講演 概要, 156-57 (1982).

15）北館憲一郎, 谷本慶哲, 田中俊一郎, セラミックス, 20, 907-13 (1985).

16) H. E. Helms, P. W. Heitman, L. C. Lindgren and S. R. Trasher, "Ceramic Applications in Turbine Engines",
Noyes (1986) pp. 106-31.

17) P. Rottenkolber, M. Langer, R.S. Storm and F. Frechette, SAE No.810523 (1981).

18）佐々木正史, 和泉隆夫, 阿知波清次, 伊藤高根, GTSJ, 13, 28-35 (1985)

19) K. T. Faber, M.D. Huang and A. G. Evans, J. Am. Ceram. Soc., 64, 296-301 (1981).

20）岐美 格, 奥野純平, 牧野州秀, “工業熱力学”, 森北出 版 (1972) p. 151 